\title{
Vanillin a Food Additive Ameliorates Harmaline Induced Tremor in Rats
}

Abdulrahman Al Asmari ${ }^{*}$, Lubna Al Otaibi ${ }^{2}$, Faisal Kunnathodi' ${ }^{1}$ Fahad Abdullah Al Ghulaydhawi ${ }^{3}$ and Mohammed Arshaduddin ${ }^{1}$

${ }^{1}$ Research Center, Prince Sultan Military Medical City, Saudi Arabia

${ }^{2}$ Department of Dentistry, Prince Sultan Military Medical City, Saudi Arabia

${ }^{3}$ King Khalid University Hospital, Riyadh 11159, Saudi Arabia

"Correspondence to:

Abdulrahman Al Asmari, $\mathrm{PhD}$

Research Center, Prince Sultan Military Medical

City, P.O. Box 7897 (777-S)

Riyadh 11159, Saudi Arabia

E-mail: abdulrahman.alasmari@gmail.com

Received: January 28, 2016

Accepted: March 07, 2016

Published: March 09, 2016

Citation: Asmari AA, Otaibi LA, Kunnathodi F, Ghulaydhawi FAA, Arshaduddin M. 2016. Vanillin A Food Additive Ameliorates Harmaline Induced Tremor in Rats.J Neurol Exp Neurosci 2(1): 2-8.

Copyright: ( 2016 Asmari et al. This is an Open Access article distributed under the terms of the Creative Commons Attribution 4.0 International License (CC-BY) (http://creativecommons. org/licenses/by/4.0/) which permits commercial use, including reproduction, adaptation, and distribution of the article provided the original author and source are credited.

Published by United Scientific Group

\section{Abstract}

Background: Essential tremor (ET) is a common neurological disorder. Genetic, environmental and dietary factors have been suggested to contribute to ET. The present study investigates the effect of vanillin, a polyphenol food additive with strong neuroprotective activity in harmaline induced tremors in rats.

Methods: Seventy two male Sprague Dawley rats weighing $115 \pm 5 \mathrm{~g}$ were divided into twelve groups of six animals each. Four groups were allotted to each study. Vanillin $(50 \mathrm{mg}, 100 \mathrm{mg}$, and $200 \mathrm{mg} / \mathrm{kg}$ ) was administered ten minutes after the induction of tremor (therapeutic study) and before the induction of tremor (prophylactic study). In the acute prophylactic study, it was administered $30 \mathrm{~m}$ before and for sub-acute prophylactic study it was administered 7 days before the induction of tremor. Harmaline $(10 \mathrm{mg} / \mathrm{kg}$, IP.), was used for the induction of tremor. The latency of onset, duration, intensity of tremor and tremor index were recorded.

Results: Harmaline treatment produced characteristic tremor that lasted for more than 2 hours. Vanillin both in therapeutic and prophylactic studies failed to produce any significant change in the latency of onset of tremor. The duration of tremor was significantly reduced in both therapeutic and acute prophylactic treatment, but the reduction was not significant in sub-acute prophylactic studies, while the intensity of tremor and tremor index were significantly reduced in both the therapeutic and prophylactic studies.

Discussion: The present study suggests that vanillin ameliorates harmaline induced tremor in rats. Further detailed studies are warranted to understand the mechanism of this protection.

\section{Keywords}

Harmaline, Tremor, Vanillin, Attenuate, Intensity, Duration

\section{Introduction}

Essential tremor (ET) also referred to as benign or familial tremor is a hyperkinetic movement disorder characterized by the uncontrolled rhythmic oscillations of the different parts of the body, during voluntary movements. Tremors are generally noticed in the hands and arms but other parts such as head, jaw, chin, palate, trunk and legs may also be affected. ET is one of the most common neurological disorders with a wide variation in prevalence among different communities and populations [1-3]. According to a recent estimate 
around $2.2 \%$ of the population in the United states are affected by ET, which is 7 times more than the prevalence of Parkinson's disease that affects about $0.15-0.3 \%$ of the population $[4,5]$. Although ET is considered as a benign problem, it has a profound influence on the quality of life with more than half of the patients above the age of 65 seeking medical treatment [6]. Furthermore, around $15 \%$ of the patients are unable to continue with their work due to the high amplitude of tremor and resulting multifunctional disabilities $[7,8]$.

The pathophysiology of ET is not clear and the exact mechanism of tremor is not well established. Different factors including genetic [9], environmental [10], and dietary factors $[11,12]$, have been reported to be associated with ET. On the other hand, limited efficacy and noncompliance due to the common side effects of the available therapeutic options make it necessary for the exploration of new drugs specifically designed for treatment of tremor [13].

A recent study demonstrated the suppressive effect of safranal, an active constituent of a food additive Saffron in harmaline induced tremor [14]. Food additives specially that contain polyphenols are promising compounds for the treatment of different neurological diseases [15]. Dietary phenols have been found to be useful agents for the modulation of brain function [16], and in the mitigation of brain diseases [17]. Consumption of different fruits and vegetables with a high content of polyphenols was found to be helpful in decreasing dementia and cognitive impairment [18, 19]. Supplementation of the diet with blue berries, a rich source of polyphenols was observed to increase the precursor cells in the dentate gyrus of rats [20], suggesting a link between polyphenols and neurogenesis [21]. Furthermore, polyphenols and their metabolites exert modulatory actions on different signaling pathways [22].

Vanillin (VLN), a O-methyl catechol (4-hydroxy-3methoxybenzaldehyde) polyphenol is a flavor compound extracted from vanilla beans. It is widely used as an additive in food, medicine and perfume $[23,24]$, with an estimated annual consumption of more than 2000 tons all over the world [25]. Vanillin has been reported to ameliorate depression like behaviors in rats [26], and has a preventive effect in animal model of Huntington's disease [27]. In addition, vanillin also possesses anti-inflammatory [28], anti-mutagenic [23] and antitumor properties [29].

Harmaline is a $\beta$ carboline alkaloid ( $\beta \mathrm{CA}$ ) derived from the harma plant. Systemic administration of $\beta C A$ s produces discernible postural and kinetic tremor in experimental animals such as mice, rats, rabbits and monkeys [30-32]. Harmaline induced tremor is used as a model for preclinical testing of drugs against tremor [14] and drugs used to treat essential tremor have been observed to suppress harmaline induced tremor [31]. Keeping in view the wide use of vanillin and the neuroprotective potential of vanillin, the present study was designed to examine the effect of vanillin on harmaline induced tremor in rats.

\section{Materials and Methods}

All animal experiments were performed in accordance with the animal protection guidelines of the Institutional Research and Ethics Committee of Prince Sultan Military Medical City. Male Sprague Dawley rats weighing $115 \pm 5 \mathrm{~g}$ were obtained from the animal facility of the institute. They were housed under standard conditions at a temperature of $23 \pm 1{ }^{\circ} \mathrm{C}, 12 \mathrm{~L}: 12 \mathrm{D}$ cycle and had free access to food and water. The animals were divided into three batches. Each batch was made up of four groups with six rats each. Group one was given harmaline and the other three groups were administered vanillin in different doses either before or after the induction of tremor according to the type of study.

\section{Drugs and administration}

Harmaline (Sigma Aldrich, USA) was dissolved in saline and administered by intra-peritoneal injection at a dose of 10 $\mathrm{mg} / \mathrm{kg}$. Vanillin (Merck, Germany) was dissolved in saline and administered by gavage at 50,100 and $200 \mathrm{mg} / \mathrm{kg}$. The selection of different doses was based on earlier literature and on our pilot studies [33-35].

Based on the duration and time of treatment i.e. before or after the induction of tremor and for the sake of convenience the studies were designated as; acute therapeutic, acute prophylactic and sub-acute prophylactic. The animals in the therapeutic study were administered vanillin by gavage at three different doses $(50,100$, and $200 \mathrm{mg} / \mathrm{kg}), 10$ minutes after the induction of tremor by a single injection of harmaline $(10 \mathrm{mg} / \mathrm{kg})$. In the acute and sub-acute prophylactic studies vanillin was administered $30 \mathrm{~m}$ and 7 days respectively before the induction of tremor. The protocol of drug administration is depicted in Figure 1.

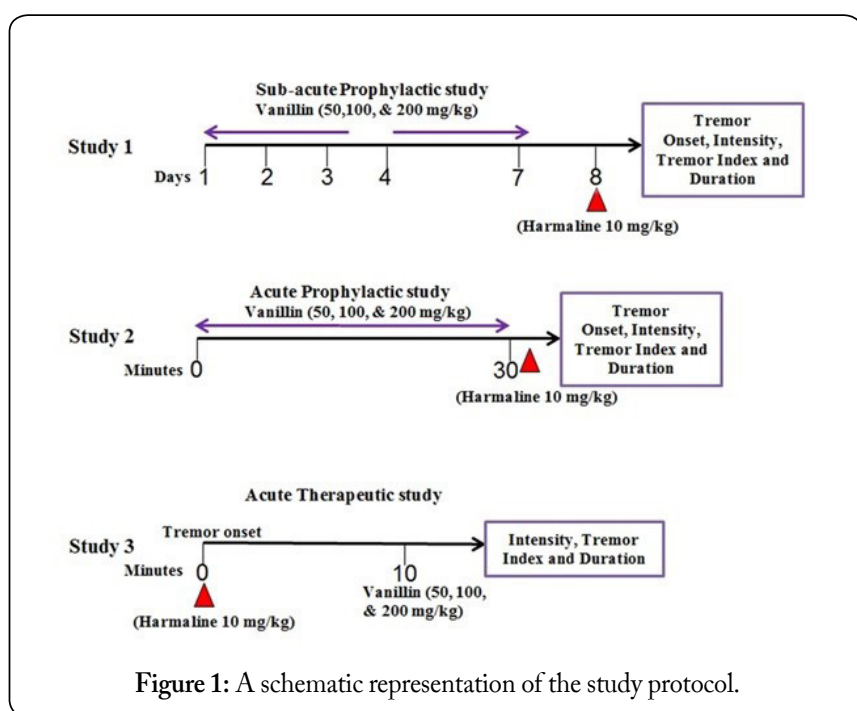

\section{Tremor grading}

The occurrence of tremors was rated by an observer blinded to treatment protocol as described earlier [36]. Different members of the team performed the assessment of tremor. One member prepared and administered the drugs and recorded the onset, while the intensities and duration of the tremor was recorded by another member of the team, who was not aware of the groups and the treatment to which each animal belongs. 
The period between the injection of harmaline and the appearance of the first symptoms of tremors was recorded as the latency of onset of tremors. The duration of tremors was defined as the time between the onset and complete disappearance of tremors. The intensity of tremors was assessed at regular intervals (every 10 minutes) until the tremors completely subsided and the animals became normal. The clinical grading of the intensity of tremors was done as reported earlier [36, 37]: no tremor $=0$, mild tremor $=1$, moderate intermittent tremor $=2$, moderate persistent tremor $=3$ and pronounced severe tremor $=4$. Tremor index was expressed as the total sum of the intensity score for the entire duration of tremor as per the method of Suemaru et al. [38]. Harmaline induces tremor with a frequency of $10-13 \mathrm{~Hz}$ in rats $[36,39]$.

\section{Statistical analysis}

The results are presented as mean \pm standard error. One way analysis of variance (ANOVA) followed by Dunnett's multiple comparison test were used to determine the level of significance. Difference with a $\mathrm{P}$ value of $<0.05$ was considered as significant.

(a)

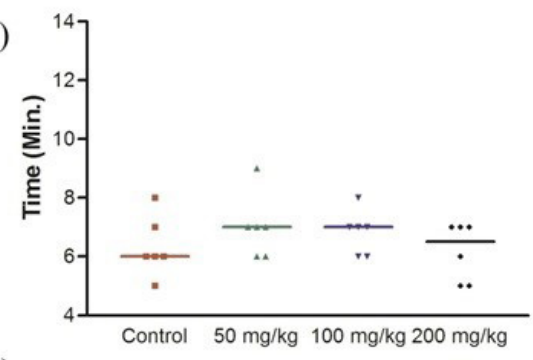

(b)

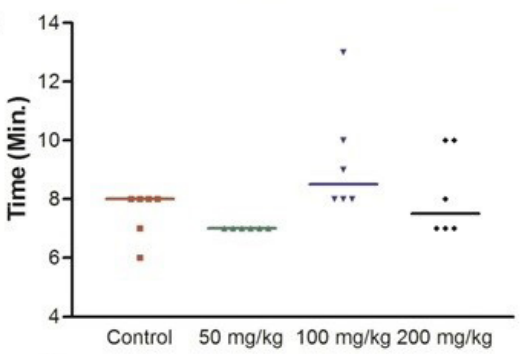

(c)

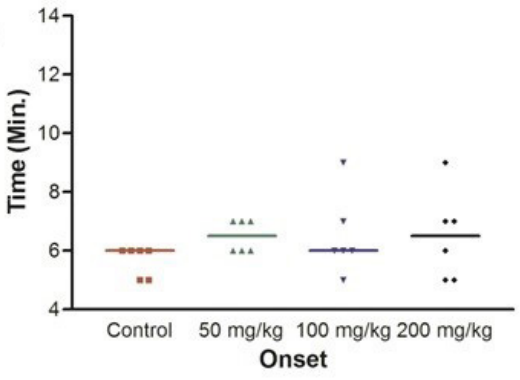

Figure 2: Effect of vanillin treatment on onset of harmaline induced tremor. (a) Acute therapeutic (b) Acute prophylactic (c) Sub-acute prophylactic.

\section{Results}

\section{Effect of vanillin on latency of onset of tremor}

Treatment of rats with harmaline produced characteristic tremors starting within 5-8 minutes of its administration. The tremor was noticed first in the head and then spread to the whole body. Before the onset of tremor, the animals showed reduced mobility and mild pilo erection. Although the tremor was observed at both rest and at movement, it was more pronounced when the animals were moving or not leaning against the wall of the cage. The tremor lasted for around 120 to 160 minutes.

Pretreatment of animals at different doses of vanillin either 30 minutes (acute prophylactic study) or 7 days before (sub-acute prophylactic study) the induction of tremor failed to produce any statistically significant changes in the latency of onset of tremor (Figure $2 \mathrm{~b}$ and $2 \mathrm{c}$ ).

\section{Effect of vanillin on duration of tremor}

The mean duration of tremor in harmaline treated animals ranged between 120 to 160 minutes. In the therapeutic study a statistically significant $(P<0.01)$ reduction in the duration of tremor was observed only in animals treated at the highest dose of vanillin (Figure 3a). On the contrary acute prophylactic treatment with vanillin resulted in a statistically significant $(\mathrm{P}<0.05)$ reduction in the total duration of tremor in the 50 and $200 \mathrm{mg} / \mathrm{kg}$ vanillin treated groups (Figure 3b). The sub-acute prophylactic (7 days) treatment of animals with the different doses of vanillin resulted in a statistically insignificant reduction in the total duration of tremor (Figure 3c).

(a)

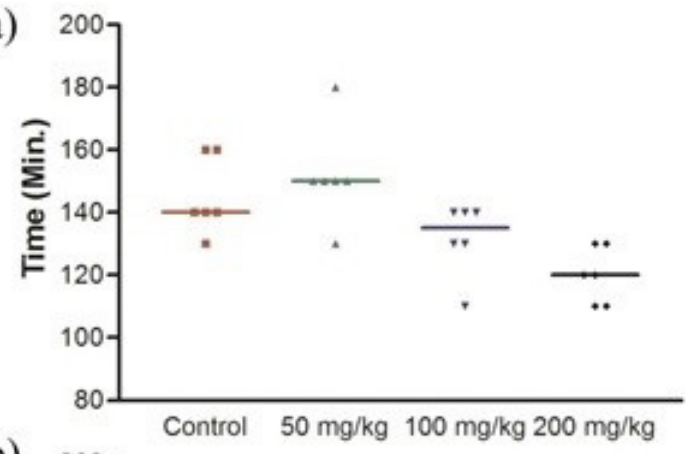

(b)

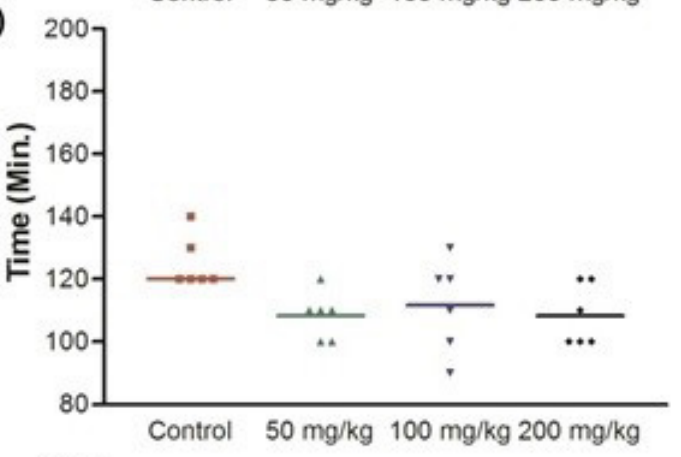

(c)

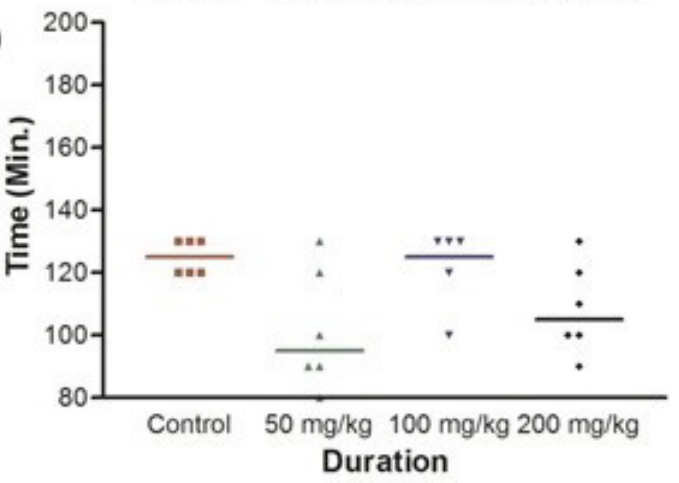

Figure 3: Effect of vanillin treatment on duration of harmaline induced tremor. (a) Acute therapeutic (b) Acute prophylactic (c) Sub-acute prophylactic. 


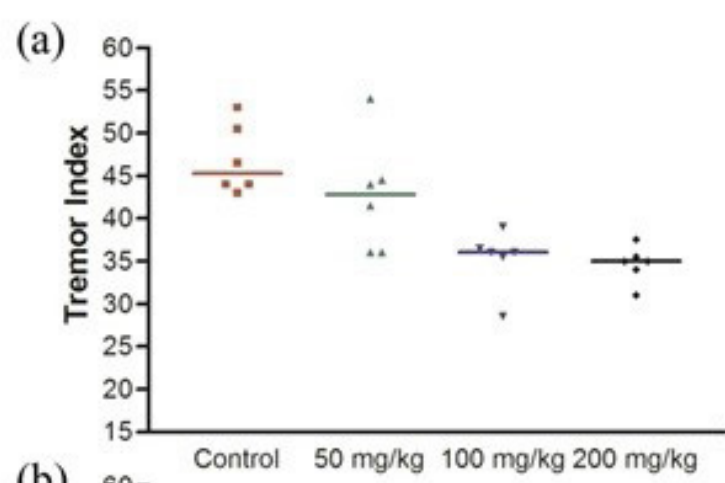

(b)
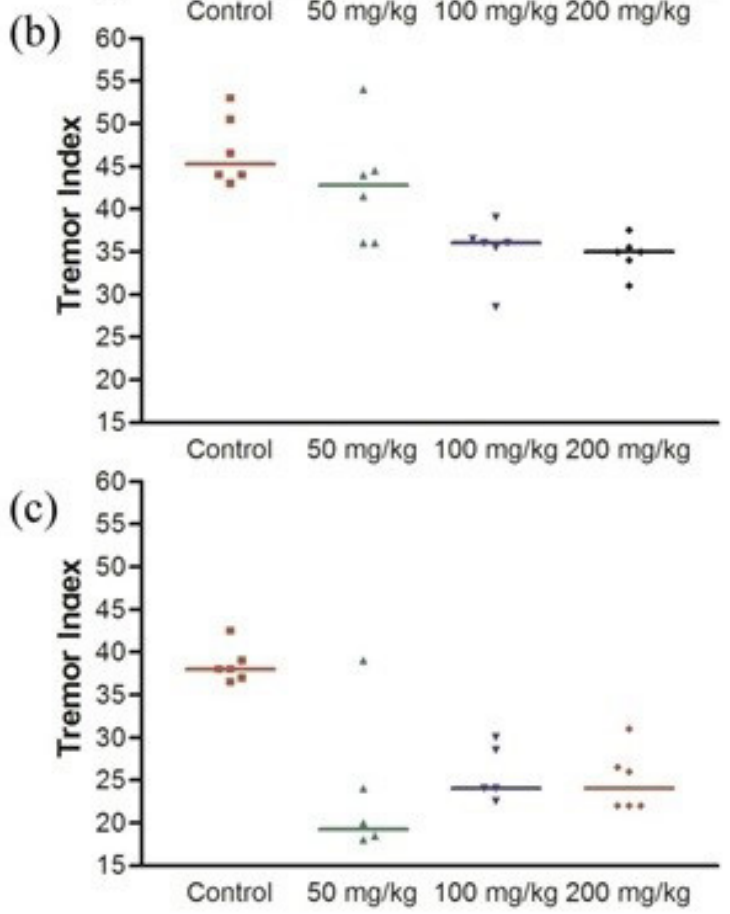

Figure 4: Effect of vanillin treatment on index of harmaline induced tremor. (a) Acute therapeutic (b) Acute prophylactic (c) Sub-acute prophylactic.

\section{Effect of vanillin on the tremor intensity and index}

The tremor intensity index in the harmaline treated animals ranged between, 39-47. The results of our acute therapeutic study showed a significant $(\mathrm{P}<0.01)$ decrease in the tremor intensity index of the animals treated with 100 and $200 \mathrm{mg} / \mathrm{kg}$ of vanillin (Figure 4a). On the other hand, both acute and sub-acute prophylactic treatment of animals with vanillin resulted in a significant $(P<0.01)$ reduction in the tremor intensity index in all the treated groups (Figure $4 \mathrm{~b}$ and 4c).

The changes in the intensity of tremor in relation to time for the therapeutic, acute prophylactic and sub-acute prophylactic studies are given in Figure 5, 6 and 7 respectively. Treatment of animals with harmaline produced a consistently high intensity $(4 \pm 0)$ of tremor during the first hour and started to decline thereafter. In the therapeutic regimen of treatment, the intensity of tremor was significantly reduced by all the three doses of vanillin at 30 minutes $(\mathrm{P}<0.01)$ and 60 minutes $(\mathrm{P}<0.001)$. Subsequently only the medium $(100 \mathrm{mg} / \mathrm{kg}$ : $\mathrm{P}<0.05$ and 0.01$)$ and the high dose $(200 \mathrm{mg} / \mathrm{kg}: \mathrm{P}<0.01$ and 0.001 ) of vanillin were effective in significantly reducing

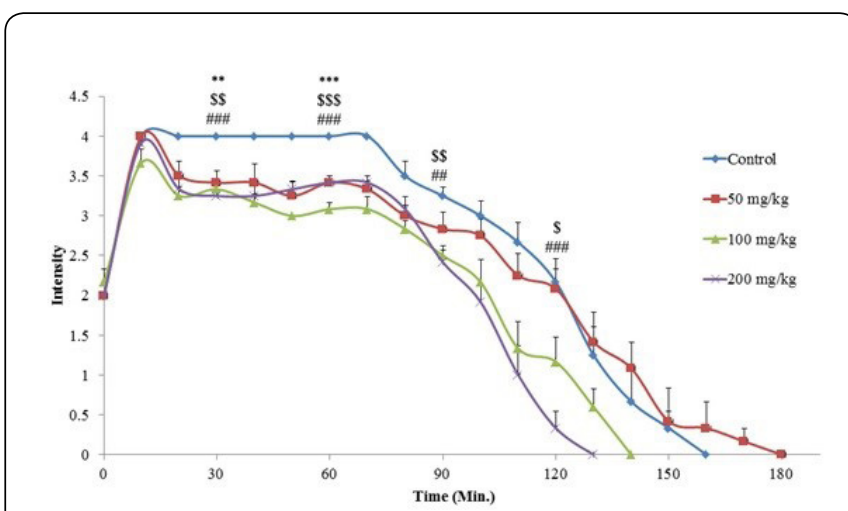

Figure 5: Effect of acute therapeutic treatment with vanillin on intensity of harmaline induced tremor at various time points. Values are mean \pm S.E.M. ${ }^{* *} \mathrm{P}$ $\leq 0.01,{ }^{\text {*** }} \mathrm{P} \leq 0.001$ indicates significance of control $\mathrm{Vs} 50 \mathrm{mg} / \mathrm{kg}$ vanillin, $\$ \mathrm{P} \leq$ $0.05, \$ \$ \mathrm{P} \leq 0.01, \$ \$ \$ \mathrm{P} \leq 0.001$ indicates significance of control Vs $100 \mathrm{mg} / \mathrm{kg}$ vanillin and \#\# $\mathrm{P} \leq 0.01$, \#\# $\mathrm{P} \leq 0.001$ indicates significance of control Vs 200 $\mathrm{mg} / \mathrm{kg}$ vanillin respectively, using ANOVA followed by post hoc comparison by Dunnett's multiple comparison test.

the intensity of tremor at 90 and 120 minutes respectively (Figure 5). On the other hand, in both acute and sub-acute prophylactic studies a significant difference was observed in the intensity of tremor at different time intervals between the vanillin treated and harmaline alone treated animals, however the effect was not dose dependent (Figure 6 and 7).

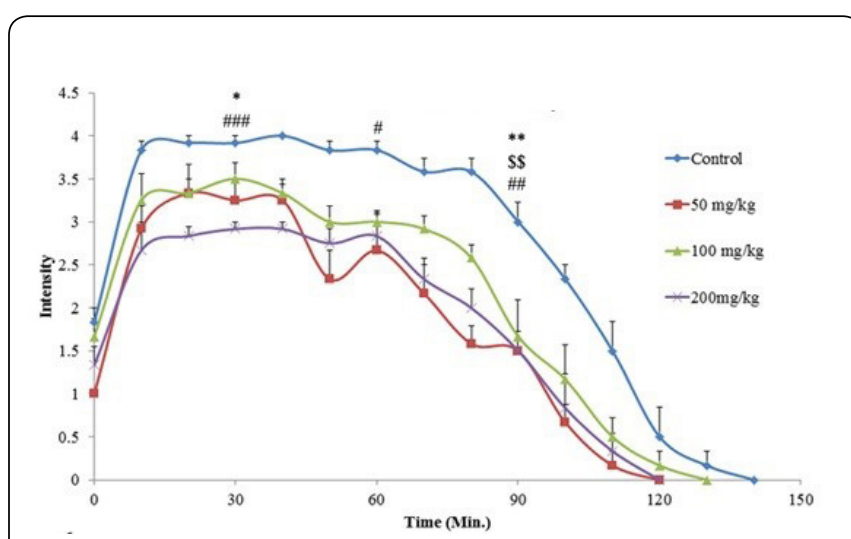

Figure 6: Effect of acute prophylactic treatment with vanillin on intensity of harmaline induced tremor at various time points. Values are mean \pm S.E.M. ${ }^{*} \mathrm{P} \leq 0.05,{ }^{* *} \mathrm{P} \leq 0.01$ indicates significance of control $\mathrm{Vs} 50 \mathrm{mg} / \mathrm{kg}$ vanillin, $\$ \$ \mathrm{P} \leq 0.01$ indicates significance of control Vs $100 \mathrm{mg} / \mathrm{kg}$ vanillin and \# $\mathrm{P} \leq$ 0.05 , \#\# $\mathrm{P} \leq 0.01$, \#\# $\mathrm{P} \leq 0.001$ indicates significance of control Vs $200 \mathrm{mg}$ / $\mathrm{kg}$ vanillin respectively, using ANOVA followed by post hoc comparison by Dunnett's multiple comparison test.

\section{Discussion}

Harmaline induced tremor is a widely used animal model of essential tremor. This study was carried out to assess the effect of vanillin, a polyphenol and a commonly used food additive and flavoring agent with strong neuroprotective properties on harmaline induced tremors in rats. Both therapeutic and prophylactic treatment regimens were used to study the efficacy of vanillin against harmaline induced tremor.

Administration of harmaline produced tremors that lasted for more than two hours. The intensity of tremor was severe during the first hour and then declined gradually and 


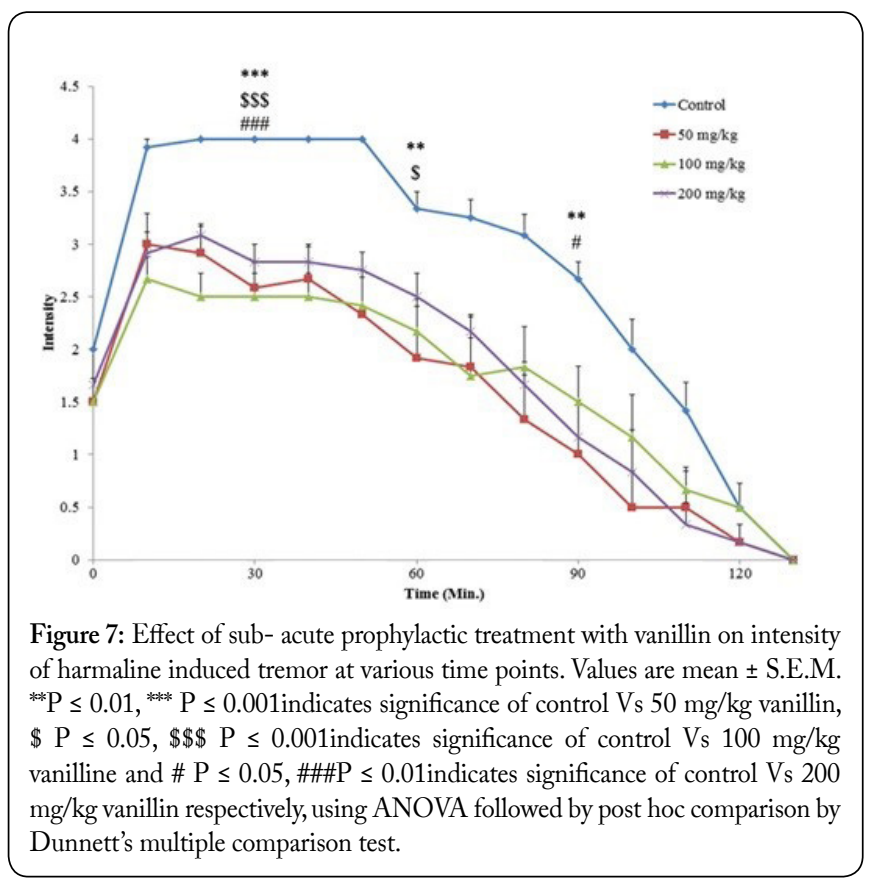

the animals were free of tremor at 2-3 hours after the onset of tremor. Vanillin treatment had an attenuating effect on harmaline induced tremor. Administration of vanillin both before and after the induction of tremor reduced the duration and intensity of tremor (Figure 3 and 4). Our findings are supported by recent studies [14], wherein beneficial effects of saffron another food additive were observed in harmaline induced tremors. Clinical studies have also indicated an association between dietary factors and essential tremor [11, 12]. Vanillin is a polyphenol and dietary polyphenols have been reported to act as modulators of brain function [16]. Furthermore, vanillin has been observed to act as a potent neuroprotective agent in models of Huntington's disease, neuropathic pain and brain ischemia [27, 40-42] and has been suggested to possess brain protective properties [24], which are evident in our study (Figure 3 and 4).

The exact anatomy and the mechanism of essential tremor and harmaline induced tremor are not clear and well defined $[43,44]$. In addition, essential tremor is not a single entity but a cluster of disorders [4] similar to harmaline induced tremor, which also involves more than one mechanism [43]. Modulation of any one or more of these mechanisms may be helpful in the attenuation of tremor.

Harmaline induced tremor is similar to centrally induced tremor. It acts on the olivary nucleus, that is considered as a pace maker for the generation of tremor and triggers a synchronous olivary discharge through alternating phases of membrane hyper polarization and rebound depolarization [44], which then spreads to other areas of the brain [45]. Drugs with anesthetic and antinociceptive properties have been observed to act as anti tremorogenic agents and reduce the latency of onset, duration and intensity of harmaline induced tremor $[14,37]$ through a reduction in neuronal excitability. The anti-tremor effect of vanillin as observed in this study may be assigned to its strong antinociceptive effects [41]. Vanillin also showed an alleviating effects on allodynia in chronic constriction nerve injury [40]. Furthermore, vanillin was reported to reduce neuronal excitability and possess strong anti-epileptic potential against maximal electro shock and pentylenetetrazole induced seizures [46, 47].

It has been suggested that harmaline induced tremor is mediated by voltage oscillations in the inferior olivary neurons that rely on low and high threshold calcium conductance and potassium currents [48]. A low threshold calcium channel antagonist 1-Octanol, was observed to be effective in suppressing harmaline induced tremor and it was hypothesized that $\mathrm{T}$ type calcium channel inhibitors may be helpful against essential tremor [49], which was confirmed by the recent studies, that point out a strong role of $\mathrm{T}$ type calcium channels in harmaline induced tremors. Handforth et al. [31] demonstrated that 5 different $\mathrm{T}$ type calcium channel antagonists suppressed tremors in both harmaline induced and Cav3-1 deficient mice models of tremor. Vanillin has a strong inhibitory effect on calcium channels [50] and prevents the initial cell depolarization and alters the final intracellular calcium levels, through its modulatory effects on the calcium channels [51]. The primary effect of vanillin is on the $\mathrm{L}$ type calcium channels [50], which are distributed on neuronal cell bodies, while $T$ type channels are associated with neuronal rhythmic burst firing [44, 52]. Though preliminary our observations of the inhibition of the harmaline induced tremor by vanillin, a $\mathrm{L}$ type calcium channel inhibitor, are supported by the earlier findings that suggested that both $\mathrm{L}$ and $T$ type calcium channels are involved in the genesis of tremor [53].

Although the neuronal circuitries involved in harmaline induced tremor are not well understood, the involvement of ionotropic glutamate, $\operatorname{GABA}(\mathrm{A})$ and dopamine $\mathrm{D}(2) / \mathrm{D}(3)$ receptors in the neurobiology of harmaline-induced tremor has been reported [30]. Agents that facilitate the inhibition of NMDA mediated glutamatergic pathways such as MK801, PCP have been observed to reduce the intensity of harmaline induced tremors [30, 54]. So the observed anti-tremor activity of vanillin in our study may be ascribed to its inhibitory action on NMDA receptors and signal transmission [55]. Furthermore, vanillin has been reported to provide neuroprotection against transient global ischemia by increasing the expression of $\gamma$ amino butyric acid transaminase in gerbil brains [42]. Inhibitory neurotransmission mediated by GABA has been shown to decrease the intensity of tremor [56]. Therefore, it is postulated that the anti-tremor activity of vanillin may be attributed to its GABA enhancing potential. On the other hand, a recent study by Kosmowska [57] has demonstrated a beneficial effect of dopamine D3 receptor agonists pramipexole and 7-OH-DPAT in harmaline induced tremor. Vanillin has also been observed to modulate monoamine transmission and was found to be protective in experimentally induced depression in rats by increasing the dopamine levels [26], suggesting a possible alternative mechanism for its anti-tremor activity.

Overall the results of our study indicate that vanillin has an attenuating effect in harmaline induced tremor in rats and may be used as a potential pharmacological agent for the treatment of tremor. However, the precise mechanism involved in the difference in anti-tremor activity of vanillin in acute and 
sub-acute treatment remains to be elucidated. Further detailed studies are warranted to understand the neuroprotective mechanism of vanillin in harmaline induced tremor.

\section{Acknowledgments}

The authors thank the administration of PSMMC for providing the facilities and support for this study. The authors are also thankful to Mr. Deivakadatcham Yesu Nayagam and staff of the animal house facility of the research center of PSMMC for their help in the study.

\section{References}

1. Louis ED, Ferreira JJ. 2010. How common is the most common adult movement disorder? Update on the worldwide prevalence of essential tremor. Mov Disord 25(5): 534-541. doi: 10.1002/mds.22838

2. Oh ES, Kim J-M, Kim YE, Yun JY, Kim JS, et al. 2014. The prevalence of essential tremor in elderly koreans. J Korean Med Sci 29(12): 16941698. doi: 10.3346/jkms.2014.29.12.1694

3. Tan LC, Venketasubramanian N, Ramasamy V, Gao W, Saw S-M. 2005. Prevalence of essential tremor in Singapore: a study on three races in an Asian country. Parkinsonism Relat Disord 11(4): 233-239. doi: 10.1016/j.parkreldis.2005.01.002

4. Louis ED. 2014. Re-thinking the biology of essential tremor: from models to morphology. Parkinsonism Relat Disord 20 suppl 1: S88-S93. doi: 10.1016/S1353-8020(13)70023-3

5. Louis ED, Ottman R.2014. How many people in the USA have essential tremor? Deriving a population estimate based on epidemiological data. Tremor Other Hyperkinet Mov (NY) 4: 259. doi: 10.7916/D8TT4P4B

6. Handforth A, Homanics GE, Covey DF, Krishnan K, Lee JY, et al. 2010. T-type calcium channel antagonists suppress tremor in two mouse models of essential tremor. Neuropharmacology 59(6): 380-387. doi: 10.1016/j.neuropharm.2010.05.012

7. Al Deeb S, Al Moutaery K, Arshaduddin M, Biary N, Tariq M. 2002. Effect of acute caffeine on severity of harmaline induced tremor in rats. Neurosci Lett 325(3): 216-218. doi: 10.1016/S0304-3940(02)00042-3

8. Deuschl G, Raethjen J, Hellriegel H, Elble R. 2011. Treatment of patients with essential tremor. Lancet Neurol 10(2): 148-161. doi: 10.1016/S1474-4422(10)70322-7

9. Higgins JJ, Loveless JM, Jankovic J, Patel PI. 1998. Evidence that a gene for essential tremor maps to chromosome $2 \mathrm{p}$ in four families. Mov Disord 13(6): 972-977. doi: 10.1002/mds.870130621

10. Louis ED. 2001. Etiology of essential tremor: should we be searching for environmental causes? Mov Disord 16(5): 822-829. doi: 10.1002/ mds.1183

11. Scarmeas N, Louis ED. 2007. Mediterranean diet and essential tremor. Neuroepidemiology 29(3-4): 170-177. doi: 10.1159/000111579

12. Louis ED, Keating GA, Bogen KT, Rios E, Pellegrino KM, et al. 2008. Dietary epidemiology of essential tremor: meat consumption and meat cooking practices. Neuroepidemiology 30(3): 161-166. doi: $10.1159 / 000122333$

13. Schneider SA, Deuschl G. 2014. The treatment of tremor. Neurotherapeutics 11(1): 128-138. doi: 10.1007/s13311-013-0230-5

14. Amin B, Malekzadeh M, Heidari MR, Hosseinzadeh H. 2015. Effect of Crocus sativus extracts and its active constituent safranal on the harmaline-induced tremor in mice. Iran J Basic Med Sci 18(5): 449-458.

15. Shay J, Elbaz HA, Lee I, Zielske SP, Malek MH, et al. 2015. Molecular mechanisms and therapeutic effects of (-)-epicatechin and other polyphenols in cancer, inflammation, diabetes, and neurodegeneration. Oxid Med Cell Longev 2015: 181260. doi: 10.1155/2015/181260

16. Vauzour D. 2012. Dietary polyphenols as modulators of brain functions: biological actions and molecular mechanisms underpinning their beneficial effects. Oxidative Medicine and Cellular Longevity 2012: 914273. doi: 10.1155/2012/914273

17. Rossi L, Mazzitelli S, Arciello M, Capo C, Rotilio G. 2008. Benefits from dietary polyphenols for brain aging and Alzheimer's disease. Neurochem Res 33(12): 2390-2400. doi: 10.1007/s11064-008-9696-7

18. Krikorian R, Shidler MD, Nash TA, Kalt W, Vinqvist-Tymchuk MR, et al. 2010. Blueberry supplementation improves memory in older adults. $J$ Agric Food Chem 58(7): 3996-4000. doi: 10.1021/jf9029332

19. Ebrahimi A, Schluesener H. 2012. Natural polyphenols against neurodegenerative disorders: potentials and pitfalls. Ageing Res Rev 11(2): 329-345. doi: 10.1016/j.arr.2012.01.006

20. Casadesus G, Shukitt-Hale B, Stellwagen HM, Zhu X, Lee HG, et al. 2004. Modulation of hippocampal plasticity and cognitive behavior by short-term blueberry supplementation in aged rats. Nutr Neurosci 7(56): 309-316. doi: 10.1080/10284150400020482

21. Stangl D, Thuret S. 2009. Impact of diet on adult hippocampal neurogenesis. Genes Nutr 4(4): 271-282. doi: 10.1007/s12263-0090134-5

22. Williams RJ, Spencer JP, Rice-Evans C. 2004. Flavonoids: antioxidants or signalling molecules? Free Radic Biol Med 36(7): 838-849. doi: 10.1016/j.freeradbiomed.2004.01.001

23. Ho K, Yazan LS, Ismail N, Ismail M. 2009. Apoptosis and cell cycle arrest of human colorectal cancer cell line HT-29 induced by vanillin. Cancer Epidemiol 33(2): 155-160. doi: 10.1016/j.canep.2009.06.003

24. Ho K, Yazan LS, Ismail N, Ismail M. 2011. Toxicology study of vanillin on rats via oral and intra-peritoneal administration. Food Chem Toxicol 49(1): 25-30. doi: 10.1016/j.fct.2010.08.023

25. Walton NJ, Mayer MJ, Narbad A. 2003. Vanillin. Phytochemistry 63(5): 505-515. doi: 10.1016/S0031-9422(03)00149-3

26. Xu J, Xu H, Liu Y, He H, Li G. 2015. Vanillin-induced amelioration of depression-like behaviors in rats by modulating monoamine neurotransmitters in the brain. Psychiatry Res 225(3): 509-514. doi: 10.1016/j.psychres.2014.11.056

27. Gupta S, Sharma B. 2014. Pharmacological benefits of agomelatine and vanillin in experimental model of Huntington's disease. Pharmacol Biochem Behav 122: 122-135. doi: 10.1016/j.pbb.2014.03.022

28. Lee Y, Kwon J, Khang G, Lee D. 2012. Reduction of inflammatory responses and enhancement of extracellular matrix formation by vanillin-incorporated poly (lactic-co-glycolic acid) scaffolds. Tissue Eng Part A 18(19-20): 1967-1978. doi: 10.1089/ten.TEA.2012.0001

29. Pedroso LS, Fávero GM, de Camargo LEA, Mainardes RM, Khalil NM. 2013. Effect of the o-methyl catechols apocynin, curcumin and vanillin on the cytotoxicity activity of tamoxifen.J Enzyme Inhib Med Chem 28(4): 734-740. doi: 10.3109/14756366.2012.680064

30. Paterson NE, Malekiani SA, Foreman MM, Olivier B, Hanania T. 2009. Pharmacological characterization of harmaline-induced tremor activity in mice. Eur J Pharmacol 616(1): 73-80. doi: 10.1016/j. ejphar.2009.05.031

31. Handforth A. 2012. Harmaline tremor: underlying mechanisms in a potential animal model of essential tremor. Tremor Other Hyperkinet Mov (NY) 2 pii: 02-92-769-1. doi: 10.7916/D8TD9W2P

32. Lavită SI,Aro R, Kiss B,Manto M,Duez P. 2015. The role of $\beta$-carboline alkaloids in the pathogenesis of essential tremor. Cerebellum (In Press).

33. Al Asmari A, Al Shahrani H, Al Masri N, Al Faraidi A, Elfaki I, et al. 2016. Vanillin abrogates ethanol induced gastric injury in rats via modulation of gastric secretion, oxidative stress and inflammation. Toxicology Reports 3: 105-113. doi: 10.1016/j.toxrep.2015.11.001

34. Sindhu G, Nishanthi E, Sharmila R. 2015. Nephroprotective effect of vanillic acid against cisplatin induced nephrotoxicity in wistar rats: a biochemical and molecular study. Environ Toxicol Pharmacol 39(1): 392404. doi: 10.1016/j.etap.2014.12.008

35. Bhagwat V, Chowta MN, Shoeb A, Maskeri R, Venkatesh V, et al. 2013. Evaluation of anxiolytic activity of vanillin in wistar albino rats. 
International Journal of Nutrition, Pharmacology, Neurological Diseases 3(2): 96-101. doi: 10.4103/2231-0738.112828

36. Sharma P. 1970. Mechanism of antitremorine-activity of adrenergic beta-receptor antagonists in the rat. QJExp Physiol Cogn Med Sci 55(3): 202-206. doi: 10.1113/expphysiol.1970.sp002069

37. Biary N, Arshaduddin M, Al Deeb S, Al Moutaery K, Tariq M. 2000. Effect of lidocaine on harmaline-induced tremors in the rat. Pharmacol Biochem Behav 65(1): 117-121. doi: 10.1016/S0091-3057(99)00175-6

38. Suemaru K, Araki H, Gomita Y. 2000. Involvement of 5-hydroxytryptamine $1 \mathrm{~A}$ receptors in nicotine-induced tail tremor in rats. Eur J Pharmacol 408(1): 19-23. doi: 10.1016/S00142999(00)00685-3

39. Arshaduddin M, Kadasah S, Al Deeb S, Al Moutaery K, Tariq M. 2005. Exacerbation of harmaline-induced tremor by imipramine. Pharmacol Biochem Behav 81(1): 9-14. doi: 10.1016/j.pbb.2005.01.014

40. Beaudry F, Ross A, Lema PP, Vachon P. 2010. Pharmacokinetics of vanillin and its effects on mechanical hypersensitivity in a rat model of neuropathic pain. Phytother Res 24(4): 525-530. doi: 10.1002/ptr.2975

41. Park SH, Sim YB, Choi SM, Seo YJ, Kwon MS, et al. 2009. Antinociceptive profiles and mechanisms of orally administered vanillin in the mice. Arch Pharm Res 32(11): 1643-1649. doi: 10.1007/s12272009-2119-8

42. Kim HJ, Hwang IK, Won MH. 2007. Vanillin, 4-hydroxybenzyl aldehyde and 4-hydroxybenzyl alcohol prevent hippocampal CA1 cell death following global ischemia. Brain Res 1181: 130-141. doi: 10.1016/j.brainres.2007.08.066

43. Marin-Lahoz J, Gironell A. 2015. Linking essential tremor to the cerebellum: neurochemical evidence. Cerebellum (In Press).

44. Llinas R, Yarom Y. 1986. Oscillatory properties of guinea-pig inferior olivary neurones and their pharmacological modulation: an in vitro study. J Physiol 376(1): 163-182.

45. Batini C, Buisseret-Delmas C, Conrath-Verrier M. 1981. Harmalineinduced tremor. Experimental Brain Research 42(3-4): 371-382. doi: 10.1007/BF00237502

46. Luszczki J, Wlodarczyk M, Glensk M, Marzeda E, Durmowicz D, et al. 2013. Effects of alizarin, betulin, curcumin, diosmin, linalool, menthofuran, $\alpha$-terpineol, theobromine, $\beta$-thujaplicin and vanillin against maximal electroshock-induced seizures in mice. Journal of PreClinical and Clinical Research 7(1): 40-42.
47. Menezes VH, Pai PG, Shoeb A, Srikanth D, Pradeepthi M, et al. 2012. Effect of vanillin on electrical and chemical induced seizures in rodents. American Journal of Pharm Tech Research 2(3): 946-954.

48. Llinas R, Yarom Y. 1981. Properties and distribution of ionic conductances generating electro responsiveness of mammalian inferior olivary neurones in vitro. J Physiol 315(1): 569-584. doi: 10.1113/ jphysiol.1981.sp013764

49. Sinton CM, Krosser BI, Walton KD, Llinás RR. 1989. The effectiveness of different isomers of octanol as blockers of harmaline-induced tremor. Pflugers Arch 414(1): 31-36. doi: 10.1007/BF00585623

50. Raffai G, Khang G, Vanhoutte PM. 2015. Vanillin and vanillin analogs relax porcine coronary and basilar arteries by inhibiting L-type $\mathrm{Ca}^{2+}$ channels. J Pharmacol Exp Ther 352(1): 14-22. doi: 10.1124/ jpet.114.217935

51. Abuirmeileh A,Talhouni A, Alsalahat I, Abed W. 2015. Vanillin reduces intestinal smooth muscle contractility. African Journal of Pharmacy and Pharmacology 9(2): 33-37. doi: 10.5897/AJPP2014.4074

52. Handforth A. 2015. Linking essential tremor to the cerebellum-animal model evidence. Cerebellum (In Press). doi: 10.1007/s12311-015-07500

53. Zhan X, Graf WM. 2012. Harmaline attenuates voltage-sensitive $\mathrm{Ca}^{2+}$ currents in neurons of the inferior olive. J Pharm Pharm Sci 15(5): 657668.

54. Eblen F, Löschmann P-A, Wüllner U, Turski L, Klockgether T. 1996. Effects of 7-nitroindazole, NG-nitro-1-arginine, and D-CPPene on harmaline-induced postural tremor, $\mathrm{N}$-methyl-d-aspartateinduced seizures, and lisuride-induced rotations in rats with nigral 6-hydroxydopamine lesions. Eur J Pharmacol 299(1): 9-16.

55. Aoshima H. 1996. Effects of alcohols and food additives on glutamate receptors expressed in Xenopus oocytes: specificity in the inhibition of the receptors. Biosci Biotechnol Biochem 60(3): 434-438. doi: 10.1271/ bbb. 60.434

56. Gironell A, Kulisevsky J, Barbanoj M, López-Villegas D, Hernández $\mathrm{G}$, et al. 1999. A randomized placebo-controlled comparative trial of gabapentin and propranolol in essential tremor. Arch Neurol 56(4): 475480. doi: 10.1001/archneur.56.4.475

57. Kosmowska B, Wardas J, Głowacka U, Ananthan S, Ossowska K. 2016. Pramipexole at a low dose induces beneficial effect in the harmalineinduced model of essential tremor in rats. CNS Neurosci Ther 22(1): 5362. doi: $10.1111 /$ cns. 12467 